\title{
ZnO Inverse Opals Using Colloidal-Crystal Template Assisted Hydrothermal Method
}

\author{
Xin WANG ${ }^{1,}$ a , Ming FU ${ }^{1, b,{ }^{*}}$, Cai-Xia LI ${ }^{1, c}$, Jie LONG ${ }^{1, d}$, Cui-Feng SUN ${ }^{1, e}$ \\ ${ }^{1}$ Key Laboratory of Luminescence and Optical Information, Ministry of Education, Institute of \\ Optoelectronic Technology ,Beijing Jiaotong University, Beijing 100044, P. R. China, \\ aemail:13121555@bjtu.edu.cn, bemail: mfu@bjtu.edu.cn, \\ cemail: 14121568@bjtu.edu.cn, ${ }^{\mathrm{d} e m a i l: 14121616 @ b j t u . e d u . c n,}$ \\ eemail:15126085@bjtu.edu.cn \\ ${ }^{*}$ Corresponding author: Ming Fu
}

Keywords: ZnO Inverse Opals, Colloidal-Crystal Template, Hydrothermal Method.

\begin{abstract}
Both two-dimensional (2D) $\mathrm{ZnO}$ nanobowl arrays and three-dimensional (3D) $\mathrm{ZnO}$ inverse opals were fabricated using hydrothermal method with assistance of the three-dimensional colloidal crystal templates. Scanning electron microscope measurements showed the morphological evolutions of $\mathrm{ZnO}$ from rods to 2D monolayer nanobowl arrays and 3D porous films by controlling the concentration of hydrothermal solutions and reaction time. The photonic stop $b$ and was characterized using reflections spectra presenting the 3D periodic geometry. The photoluminescence spectra indicate good crystalline quality via the hydrothermal route.
\end{abstract}

\section{Introduction}

Crystalline arrays of colloidal spheres represent one of the most promising templates for inverse opal fabrication. Porous materials are attracting considerable attention with technological applications that include separations, sensors, catalysis, bioscience and photonics [1-6].Various types of ordered porous materials, such as simple and ternary oxides, chalcogenides, non-metallic and metallic elements, and polymers[7-13],have been synthesized by three-dimensional colloidal crystal template.

Zinc oxide is a direct wide band gap semiconductor with a large excitation binding energy, which is one of the most important functional oxide nanostructures, exhibiting near-UV emission, transparent conductivity, and piezoelectricity. It has novel applications in optoelectronics, sensors, transducers and biomedical sciences $[14,15]$. Ordered $\mathrm{ZnO}$ inverse opal are useful for the applications in sensors and improved mass transportation originated from size-controlled macropores[16].

Generally, two- and three-dimensional ordered porous films are prepared with assistant of monolayer and multilayer colloidal crystal templates, respectively. Scharrer et al. [17] synthesized inverse opal $\mathrm{ZnO}$ photonic crystals by atomic layer deposition. Hydrothermal method, as a more convenient and cost effective method, has been used to produce $\mathrm{ZnO}$ layer by JinHyeok Kimet al.[18].In this work, we prepared both $2 \mathrm{D}$ and 3D ordered porous $\mathrm{ZnO}$ films with uniform color using 3D opal templates by hydrothermal method with different reaction time. Just by changing the reaction time, $2 \mathrm{D}$ or $3 \mathrm{D}$ ordered porous $\mathrm{ZnO}$ films were obtained, which exhibited clear photonic stopbands in the visible spectrum and efficient photoluminescence.

\section{Experimental}

The multilayer PS opal films were obtained on the Si coated with $\mathrm{ZnO}$ substrates using vertical deposition technique [19]. The Si coated with $\mathrm{ZnO}$ substrates were treated by oxygen plasma before they were used for the preparation of the PS templates. For the preparation of $\mathrm{ZnO}$ porous films, $\mathrm{Zn}\left(\mathrm{NO}_{3}\right)_{2}$ and HMTA were used as reacting agents in aqueous solution. Typically, equimolar aqueous solution of $\mathrm{Zn}\left(\mathrm{NO}_{3}\right)_{2}(0.1 \mathrm{M})$ and HMTA $(0.1 \mathrm{M})$ were quickly mixed at room temperature, 
and then a piece of $\mathrm{Si}$ foil coated with $\mathrm{ZnO}$ was put into the mixture with the colloidal crystal template side up. The reaction vessel was sealed and kept at $95{ }^{\circ} \mathrm{C}$ for a certain time (typically $3 \mathrm{~h}$ ). Then the sample was taken out and rinsed in tetrahydrofuran remove the PS templates.

\section{Results and Discussion}

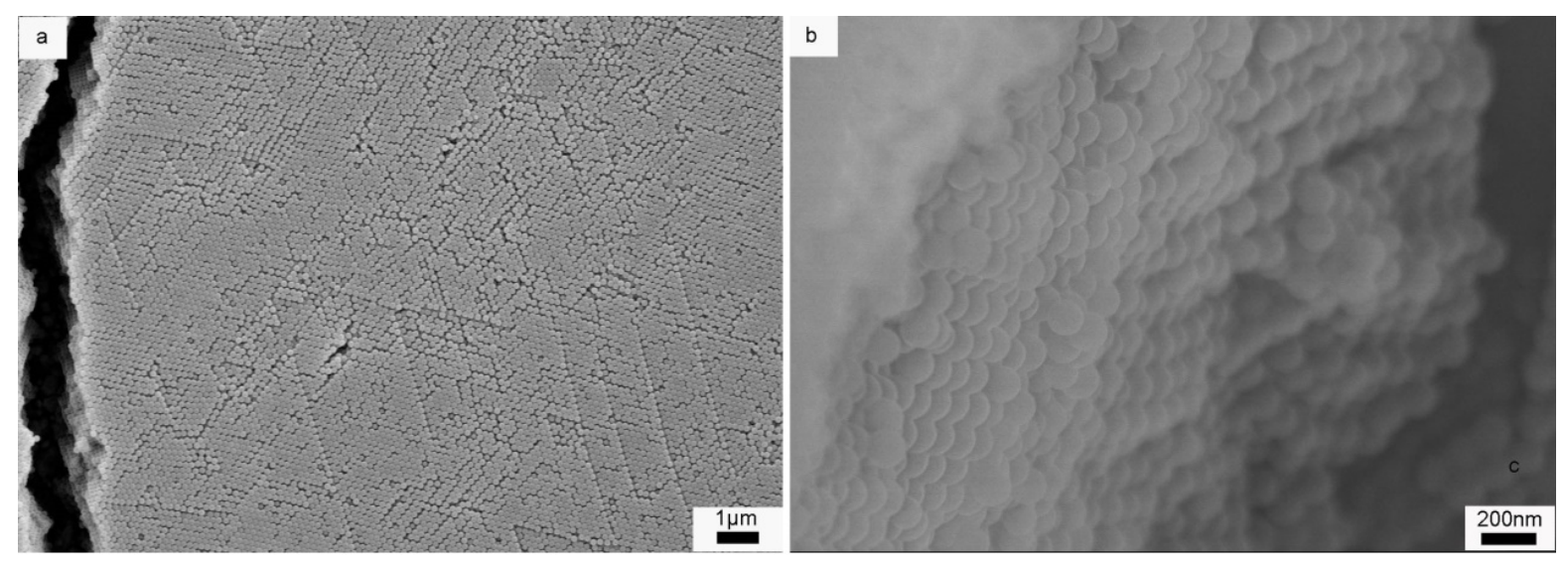

Fig.1 A typical SEM image of the PS opal templates.(a) The top views of colloidal crystal template arrays. (b)The cross section of colloidal crystal template arrays.

Fig. 1a displays the SEM image of the PS opal template showing ordered close-packed arrangement on the Si substrate. The colloidal crystal template was made from highly uniform polystyrene microspheres whose diameterswere $155 \mathrm{~nm}$. The polystyrene microspheres consist of about 30 layers and the thickness of the microsphere arrays is estimated to be $2-3 \mu \mathrm{m}$ (Fig. 1b).
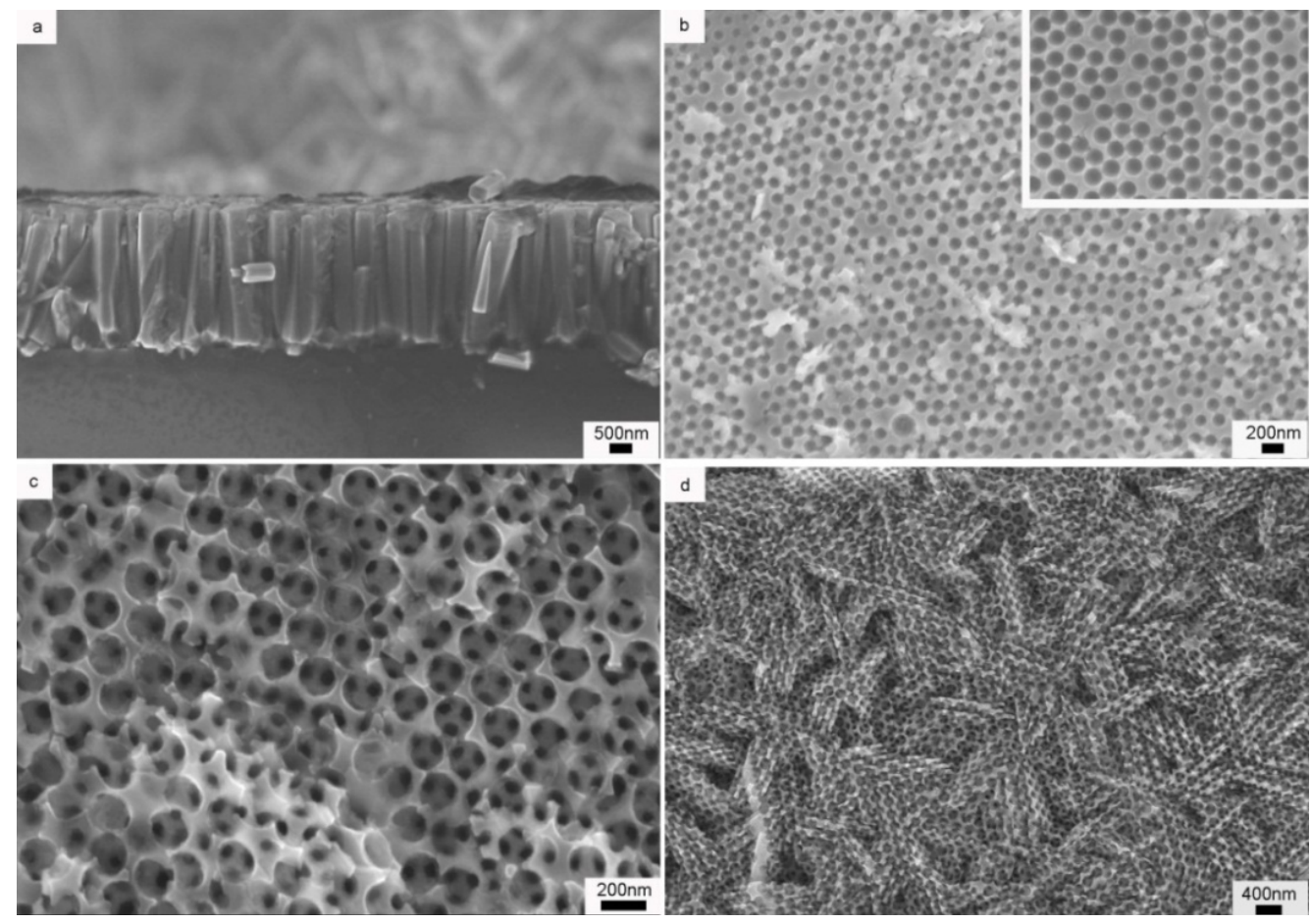

Fig.2. SEM images of $\mathrm{ZnO}$ rods films without PS (a) and the 2D ordered $\mathrm{ZnO}$ porous films with assistant of PS (b).ZnO inverse opal films synthesized in the solutions with different reaction times:(a) 3h and 6h (d).

Fig. 2ashows the SEM images of the $\mathrm{ZnO}$ rods which were synthetized in the aqueous solutions containing $\mathrm{Zn}\left(\mathrm{NO}_{3}\right)_{2}(0.1 \mathrm{M})$ and HMTA $(0.1 \mathrm{M})$ without PS. Using PS template, ordered the $\mathrm{ZnO}$ porous films can be synthesized in the same condition. Because the reaction time is so short (2h), 
the obtained $\mathrm{ZnO}$ inverse opal was 2Dordered porous films (Fig. 2b).

When the reaction time was increased,3D ZnO inverse opal was obtained. As shown in Fig. 2c,d, the $\mathrm{ZnO}$ inverse opal films were prepared in the solutions with different reaction time, $3 \mathrm{~h}$ and $6 \mathrm{~h}$, respectively. The reaction time influenced the surface morphology of $\mathrm{ZnO}$ inverse opal. When the growth time was short, most regions were uniform and the ordered pore periodicity was perfect. While the reaction time was increased, the surface pores shape became disordered.
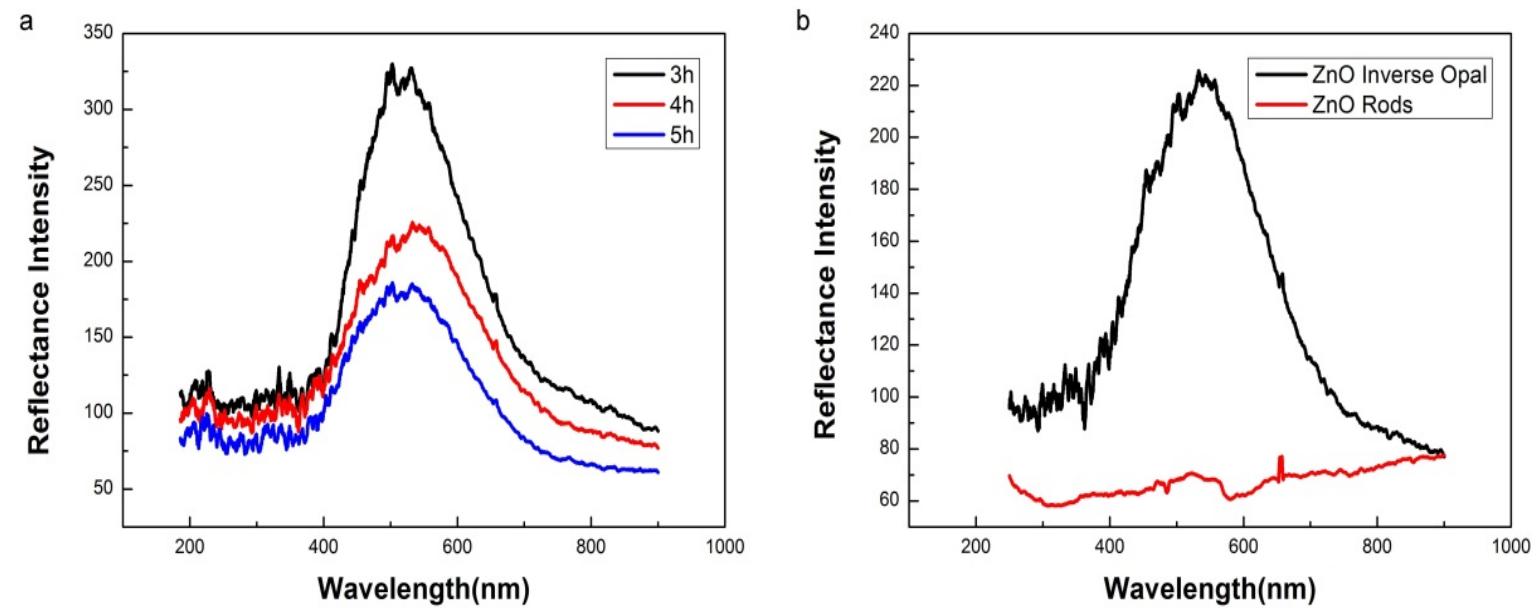

Fig.3. Reflectance spectra of $\mathrm{ZnO}$ inverted opals with different reaction time (a) and reflectance spectra compari son of $\mathrm{ZnO}$ inverted opals and $\mathrm{ZnO}$ rods (b).

The highly ordered arrangement of the $\mathrm{ZnO}$ inverse opal can be reflected by reflectance spectrum. Fig. 3a shows the normal incidence reflectance spectra of the $\mathrm{ZnO}$ inverse opal films prepared by hydrothermal method with different reaction times. The reflectance spectra show band gap position in the same visible light spectrum (about 450nm). When the reaction time was increased, the peak gradually became flat and the intensity of peak become weak. It means that the $\mathrm{ZnO}$ inverse opal became more disordered as the reaction time increase. According to Fig. $3 \mathrm{~b}, \mathrm{ZnO}$ rods do not have photonic band gap.
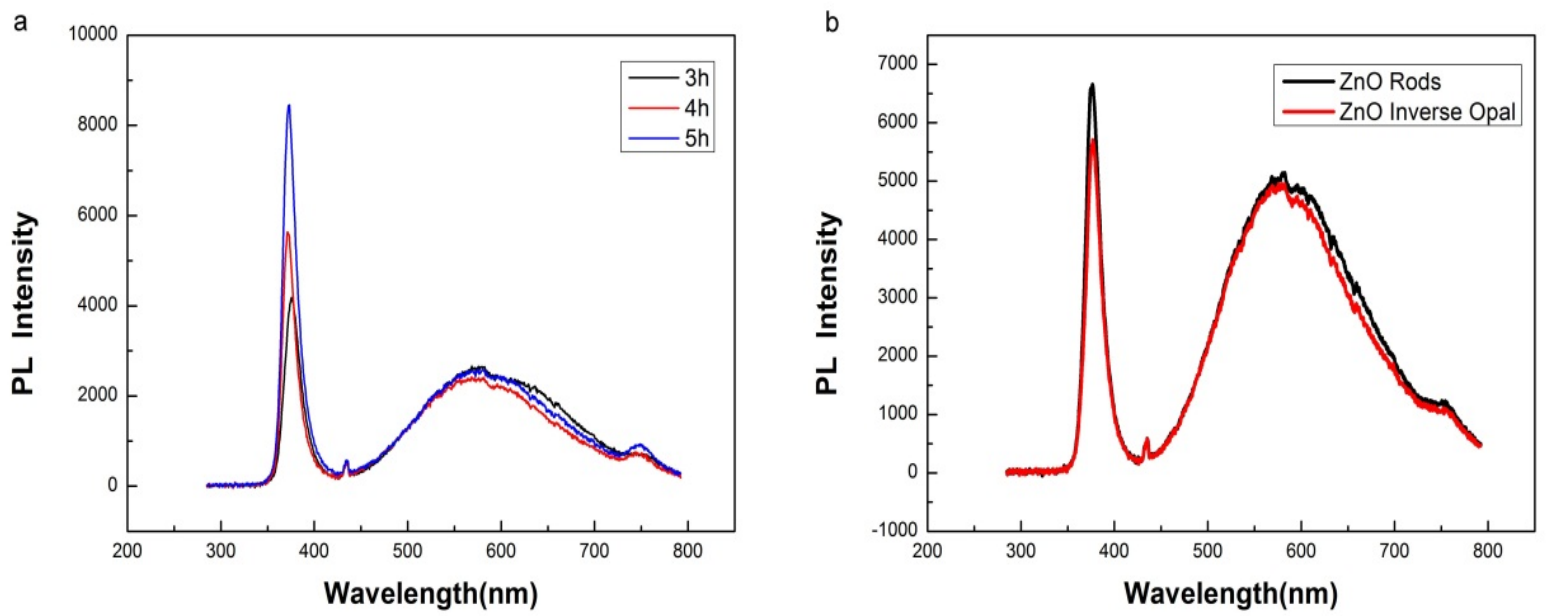

Fig.4. (a) PL spectrum of $\mathrm{ZnO}$ inverted opal obtained from different time. (b) PL spectrum of ZnO inverted opal of $\mathrm{ZnO}$ rods.

Photoluminescence measurements of the $\mathrm{ZnO}$ inverted opals show efficient emission in the UV as well as a defecte mission band at longer wavelength (Fig. 4a). This proves that $\mathrm{ZnO}$ inverted opals fabricated by hydrothermal method have high crystallization quality. And as the reaction time 
increases, ultraviolet and visible light intensity ratio (I uv / I visible) gradually increases. It indicates that $\mathrm{ZnO}$ inverse opals have higher crystallization quality as the reaction time increased. But ZnO inverse opals obtained with assistant of PS template has more defect compared with ZnO rods (Fig. 4b).

\section{Summary}

In summary, we have fabricated $2 \mathrm{D}$ and $3 \mathrm{D} \mathrm{ZnO}$ inverse opals by hydrothermal method using 3DPS templates. The ZnO inverse opals exhibited clear photonic stop bands in the visible spectrum and good crystalline quality. The morphology of $\mathrm{ZnO}$ inverse opal can be controlled by reaction time. The2D $\mathrm{ZnO}$ porous films were obtained with a reaction time of 2 hand the $3 \mathrm{D} \mathrm{ZnO}$ inverse opal films were obtained with a relative longer time. The obtained $\mathrm{ZnO}$ structures exhibit clear photonic band gaps and strong photoluminescence.

\section{Acknowledgement}

This work was supported by the Fundamental Research Funds for the Central Universities Nos. 201 5YJS171, 2015JBM098, National Natural Science Foundation of China under grants of No. 911230 25.

\section{References}

[1] Bhave R. Inorganic Membranes Synthesis, Characteristics and Applications: Synthesis, characteristics, and applications: Springer Science \& Business Media; 2012.

[2] Guliants V, Carreon M, Lin Y. Ordered mesoporous and macroporous inorganic films and membranes. Journal of Membrane Science. 2004;235:53-72.

[3] Lodahl P, Van Driel AF, Nikolaev IS, Irman A, Overgaag K, Vanmaekelbergh D, et al. Controlling the dynamics of spontaneous emission from quantum dots by photonic crystals. Nature. 2004;430:654-7.

[4] Scott RW, Yang S, Chabanis G, Coombs N, Williams D, Ozin G. Tin Dioxide Opals and Inverted Opals: Near - Ideal Microstructures for Gas Sensors. Advanced Materials. 2001;13:1468-72.

[5] Song YY, Zhang D, Gao W, Xia XH. Nonenzymatic glucose detection by using a three dimensionally ordered, macroporous platinum template. Chemistry-A European Journal. 2005;11:2177-82.

[6] Wang Y, Caruso F. Macroporous zeolitic membrane bioreactors. Advanced Functional Materials. 2004;14:1012-8.

[7] Bartlett PN, Ghanem MA, El Hallag IS, de Groot P, Zhukov A. Electrochemical deposition of macroporous magnetic networks using colloidal templates. Journal of Materials Chemistry. 2003;13:2596-602.

[8] Chai G, Yoon S, Kang S, Choi J-H, Sung Y-E, Ahn Y-S, et al. Ordered uniform porous carbons as a catalyst support in a direct methanol fuel cell. Electrochimica acta. 2004;50:823-6.

[9] Jiang P, McFarland MJ. Large-scale fabrication of wafer-size colloidal crystals, macroporous polymers and nanocomposites by spin-coating. Journal of the American Chemical Society. 2004;126:13778-86.

[10] King J, Neff C, Summers C, Park W, Blomquist S, Forsythe E, et al. High-filling-fraction inverted ZnS opals fabricated by atomic layer deposition. DTIC Document; 2003.

[11] Lei Z, Li J, Zhang Y, Lu S. Fabrication and characterization of highly-ordered periodic 
macroporous barium titanate by the sol-gel method. Journal of Materials Chemistry. 2000;10:2629-31.

[12] Velve O, Jede T, Lobo R. Porous silica via colloid crystallization. Nature. 1997;389:447-8.

[13] Yan H, Blanford CF, Holland BT, Smyrl WH, Stein A. General synthesis of periodic macroporous solids by templated salt precipitation and chemical conversion. Chemistry of Materials. 2000;12:1134-41.

[14] Pearton S, Norton D, Ip K, Heo Y, Steiner T. Recent progress in processing and properties of ZnO. Progress in materials science. 2005;50:293-340.

[15] Wang ZL. Zinc oxide nanostructures: growth, properties and applications. Journal of Physics: Condensed Matter. 2004;16:R829.

[16] Sumida T, Wada Y, Kitamura T, Yanagida S. Macroporous ZnO films electrochemically prepared by templating of opal films. Chemistry Letters. 2001:38-9.

[17] Scharrer M, Wu X, Yamilov A, Cao H, Chang RP. Fabrication of inverted opal ZnO photonic crystals by atomic layer deposition. Applied Physics Letters. 2005;86:151113.

[18] Kim JH, Andeen D, Lange FF. Hydrothermal Growth of Periodic, Single - Crystal ZnO Microrods and Microtunnels. Advanced Materials. 2006;18:2453-7.

[19] Kuai S-L, Hu X-F, Hache A, Truong V-V. High-quality colloidal photonic crystals obtained by optimizing growth parameters in a vertical deposition technique. Journal of Crystal Growth. 2004;267:317-24. 